\title{
OBSTETRIC CENTER FOR FAMILY COUNSELING - AN INNOVATIVE MODEL FOR FAMILY COUNSELING WORK AMONG MARGINALIZED GROUPS
}

\author{
Sonya Tontcheva, Teodora Evtimova \\ Department of Health Care, Faculty of Public Health, Medical University of Varna
}

\begin{abstract}
The socio-economic changes influence negatively the most vulnerable groups of society and deteriorate their social and health status. These groups are with the greatest need of being provided with integrated medical care for the family and the community. In order to increase the quality of care for maternal and child health in marginalized groups, innovative practices should be applied, the core of which is the holistic approach of the midwifery model of care.

AIM: To develop and propose a model for an Obstetric Center for Family Counseling (OCFC) and define the role of the midwife in the process of family counseling.

MATERIALS AND METHODS: We have used:

- literature related to best practices in the implementation of the Midwives Model of Care;

- a sociological method - direct anonymous survey of $4^{\text {th }}$ year trainee midwives in the Bachelor Midwife program at: Medical University of Varna, Medical University of Pleven, Rousse University "St. Kliment Ohridski" and the Higher Medical School in Bitola, Macedonia. We have also included graduates from the academic years 2014 and 2015 and experts, professors at the medical universities in Varna, Plovdiv, Pleven, and Sofia and the Rousse University, conducting specialized training in the period March - April 2016;

- a statistical method - we have used a non-parametric analysis of the results with statistical package SPSS for Windows version 19.0.0 for the analysis of the data from our own study.

RESULTS AND CONCLUSIONS: The idea of creating OCFC developed on the basis of opinion surveys of trainee midwives and experts on the attitudes and abilities of the midwife to conduct independent counselling activities. The creation of an Obstetric Center for Family Counseling is associated with the development of consultative work as promotion and prevention method regarding pregnancy and safe motherhood, support in solving medical and social and psychological problems in families from marginalized groups - unemployed, poor, uninsured with reduced social adaptation and more. The advisory activity will be related to the provision of health information, learning and developing skills associated with normal pregnancy, childbirth and newborn care, psychological, social and legal advice.
\end{abstract}

Keywords: midwife center, family counseling, marginalized

Address for correspondence:

Teodora Evtimova

Department of Health Care

Affiliate Shumen

Medical University of Varna

63 Vasil Aprilov St.

Shumen

e-mail:valitedi@abv.bg 
Obstetric Center for Family Counseling - an Innovative Model for Family Counseling Work ...

\section{INTRODUCTION}

The midwife profession is changing, driven by technological advances in health care. The atmosphere of economic constraints and political changes has put midwives in front of new opportunities and challenges.

The role of the modern midwife is focused on consulting and training, not only for women but also within the family and community, including prenatal education and preparation for parenthood, child care, sexual and reproductive health.

The International Confederation of Midwives describes the main (but not only) professional group that provides obstetrics services. According to the same organization the midwife is recognized as a professional who works in partnership with women to provide the necessary support, care and advice during pregnancy, childbirth and the postnatal period, to assist in deliveries and to provide care for the newborn. The responsibilities of the midwife also include preventive measures to promote normal birth, the detection of complications in mother and child, and providing access to medical care.

\section{MATERIALS AND METHODS}

$\diamond$ Literature relating the best practices in the implementation of the Midwives Model of Care.

$\diamond$ Sociological method - a direct anonymous survey of 4th-year students in the Bachelor's degree Midwife program of the Medical University of Varna, Medical University - Pleven, Rousse University "St. Kliment Ohridski”, Higher Medical School, Bitola, Macedonia - graduating in the academic years - 2014 and 2015, and experts, professors from the medical universities in Varna, Plovdiv, Pleven, Sofia and the Rousse University, conducting specialized training in the period March - April 2016.

$\diamond$ Statistical method - we used a non-parametric analysis of the results from the processing of our data with a statistical package SPSS for Windows version 19.0.0.

\section{RESULTS AND DISCUSSION}

The lack of involvement of a midwife in the consultative work leads to inability to satisfy the needs of promotive and preventive activities concerning the health and welfare of mothers and chil- dren. This problem has a pronounced medico-social aspect among the marginalized groups of society.

About $60 \%$ of pregnant women from the Roma ethnic group do not have a health insurance, so their pregnancy is not observed and they do not receive antenatal consultations. Increasing the qualification of the midwife in our country is a topical issue, especially in the context of the European requirements for training in "regulated professions". It has been proved, theoretically and practically, that an educated midwife could provide substantial support and information that can help every woman during pregnancy, the postnatal period, when raising children and for the overall responsible parenthood. Currently, in many countries, midwives are entitled to autonomous advisory activities, as well as assisting in normal births. All these are not clearly regulated legally in Bulgaria.

In our country there are still a number of restrictions that prevent and hinder midwives from being at the forefront. Our health care system is deprived of the resource that is the academically prepared midwife. This leads to insufficient care for pregnant women and mothers who need advice, support and encouragement - activities that midwives in the country are competent enough to perform responsibly. In this sense, midwives can and should be involved in innovative forms of active partnership with mothers and families to monitor pregnancy and raise healthy children. With the proper training they can play a crucial role with their specific practical abilities at all levels in regard to preserving the health of the mother and the child health and improving the quality of life for these women. We present a model of an Obstetric Center for Family Counseling (OCFC) - an innovative form of obstetric care aimed at overcoming inequalities in the provision of family advisory work among marginalized groups. Suchanapproachwouldhelptoprovideahighvolumeof obstetriccaretomothersinneedandfamiliesingeneral. The creation of the OCFC is associated with the development of consultative work as promotive and preventive method concerning pregnancy and safe motherhood, providing support in solving medical, social and psychological problems in families from marginal groups - unemployed, poor, uninsured individuals with reduced social adaptation, etc. (Fig. 1). 


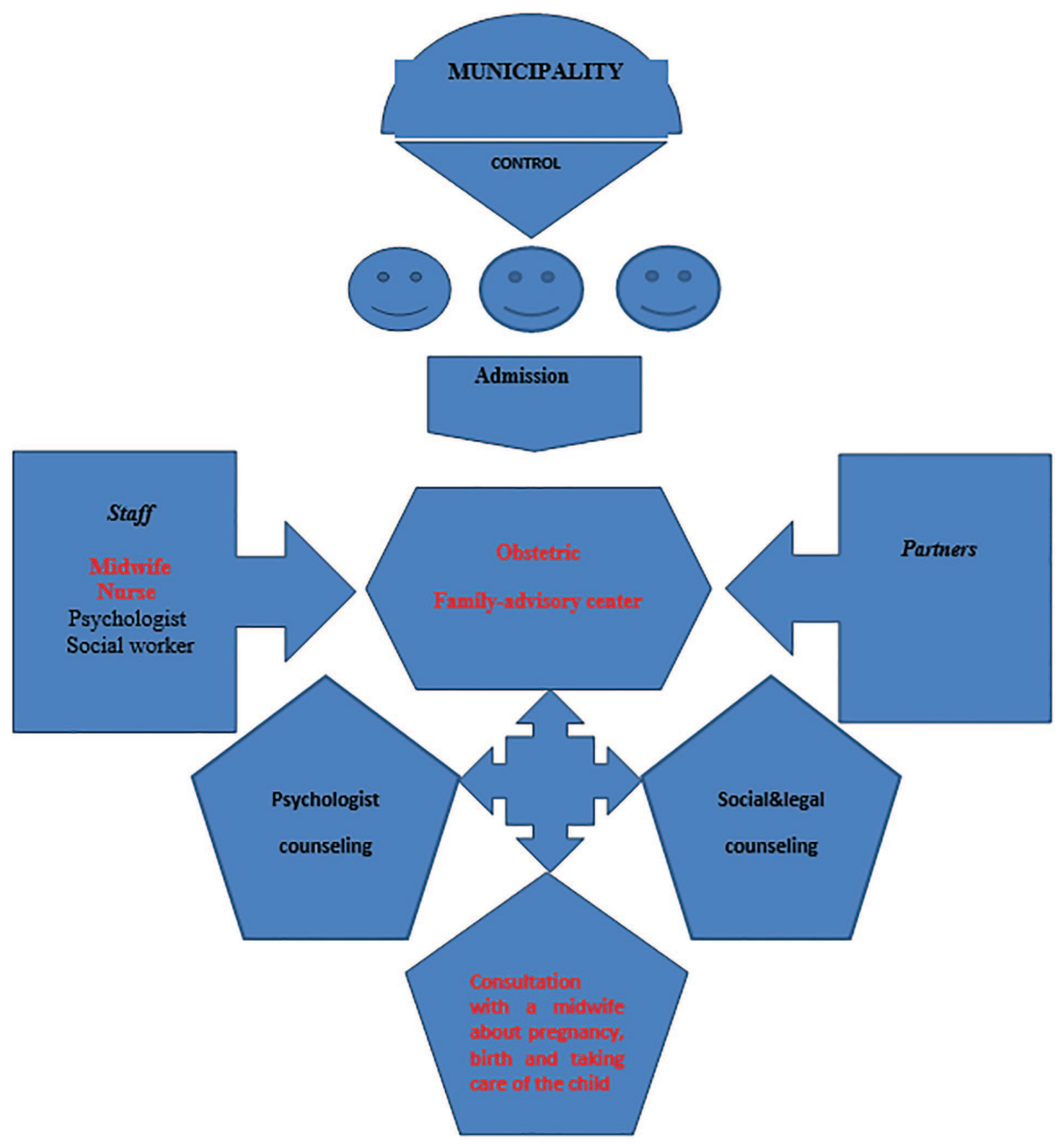

Fig. 1. Model of an Obstetric Center for Family Counseling

The advisory activity will be related to the provision of health information, learning and developing skills associated with normal pregnancy, childbirth and newborn care, psychological, social and legal advice.

The methods applied to build practical skills are lectures, role-playing games, discussions, interactive methods, and demonstrations.

The Obstetric Center for Family Counseling will be managed by a midwife with a minimum work experience of 5 years and a Master's degree in Health Care Management. The team will consist of a midwife, nurse, social worker and a psychologist.

The activity will be funded by the municipality, European projects, foundations, voluntary organizations, and individuals. With a statutory and autonomously regulated activity of the midwife, the fund- ing should be covered by the NHIF. The structure of the proposed model of the Obstetric Center for Family Counseling includes:

$\diamond$ access to the service - defining criteria for inclusion in the activities of OCFC;

$\diamond$ target groups;

$\diamond$ team conducting the activities;

$\diamond$ partners;

$\diamond$ activities carried out at the OCFC.

\section{Access to the Service}

The provision of services will be carried out on the basis of clear rules and procedures:

$\diamond$ Consumers will be included voluntarily, based on established criteria.

$\diamond$ Users of the service will be women and families at a strong medical and social risk and/or marginalized groups. 
$\diamond$ Potential users will be directed to the Center by GPs, pediatricians, obstetricians, health mediators, Social Services, Child Protection Services, social service providers, existent Family Consultation Centers and other structures that provide services to children and families in the community.

The activity of OCFC will be directed primarily towards the most deprived sections of society whose health care needs remain unmet.

Target groups can be:

$\diamond$ ethnic minorities

$\diamond$ families living in poverty

$\diamond$ unemployed

$\diamond$ disabled women

$\diamond$ single parents/insufficient family support

$\diamond$ pregnant teenage/young parents

$\diamond$ large families with three or more children

$\diamond$ women refugees, including unaccompanied minors and pregnant mothers with children

$\diamond$ women victims of violence

Activities that will be implemented at the OCFC will cover the period from pregnancy planning, pregnancy, childbirth, postnatal period and taking care of the child up to 1 year of age.

Consultation with a midwife during pregnancy:

$\diamond$ education of parents and support to develop parenting skills to care for young children;

$\diamond$ information about pregnancy;

$\diamond$ hygiene of pregnancy;

$\diamond$ information about fetal development;

$\diamond$ diet;

$\diamond$ preparation for childbirth - preparing a birth plan;

$\diamond$ preparation for lactation - physiology, the benefits of breast milk, steps to successful breastfeeding;

$\diamond$ parent education and support for responsible parenthood;

$\diamond$ preparation for the implementation of newborn care at home.

Consultation with a midwife/nurse in the postnatal period and the period of early childhood development:

$\diamond$ tracking the overall condition of the mother; $\diamond$ breast care for new mothers;

$\diamond$ monitoring the surgical wound (if there is any);

$\diamond$ monitoring of the bleeding and the recovery of the genital area;

$\diamond$ health promotion and prevention of risks to child health and development;

$\diamond$ newborn care;

$\diamond$ conditioning;

$\diamond$ massage and gymnastics;

$\diamond$ anthropometry;

$\diamond$ monitoring of the neuro-psychological development of the child.

Psychological Counseling:

$\diamond$ psychological prophylaxis of pregnant women;

$\diamond$ prevention of pre- and postpartum depression in parents;

$\diamond$ building the mother-child relationship;

$\diamond$ creating a supportive environment in the family;

$\diamond$ developing parental skills;

$\diamond$ early stimulation of brain development of the child - a predictor of normal childhood development;

$\diamond$ emotional support for women during pregnancy, childbirth and the postpartum period.

Social and Legal Counseling:

$\diamond$ providing legal support on matters relating to maternity leave;

$\diamond$ consultation on options for financial security according to the Family Allowances Act and the regulations for its implementation;

$\diamond$ information related to patients' rights and access to health care;

$\diamond$ mediation to improve social resources of families;

$\diamond$ building inter-institutional relations and referral to structures related to pregnancy and maternity.

\section{Control Authorities}

The activity of OCFC should be publicly presented and controlled. Control functions may have:

$\diamond$ Ministry of Health;

$\diamond$ Municipality - Directorate of Social Policy and Health, Directorate of Education, Science and 
Culture, Department of Economics, Municipal Property and European Programs;

$\diamond$ Public Council;

$\diamond$ Bulgarian Association of Health Care Professionals (BAHCP).

A comparative analysis of the groups was conducted on the role of the midwife in the process of family counseling activities to improve women's health with a focus on marginalized groups. An essential factor for the effective work of the midwife is the trust of her patients in the activities she performs within her jurisdiction. A comparison between all groups surveyed - experts, clients, trainees, patients and specialists, was performed.

Analysis of the results indicated unreserved confidence of the five groups of respondents in the work of the midwife. Highly indicative is the trust of patients (98.8\%) and clients (90.4\%), which are direct beneficiaries of midwife care during pregnancy, childbirth, postnatal period and the raising of the child (Fig. 2) .

The attitudes and the willingness of experts and trainees to carry out autonomous obstetric activity is expressed by their opinion that a Bulgarian OCFC could become a reality. Convinced of this are the two groups - trainees $(75.58 \%)$ and experts (66.67\%) (Fig. 3).

The results are encouraging. Need and trust are present. The experts also support the opening of an OCFC and this is a reason to seek legislative options, lobbies and initiatives by Parliament.

What is the readiness to establish an OCFC?

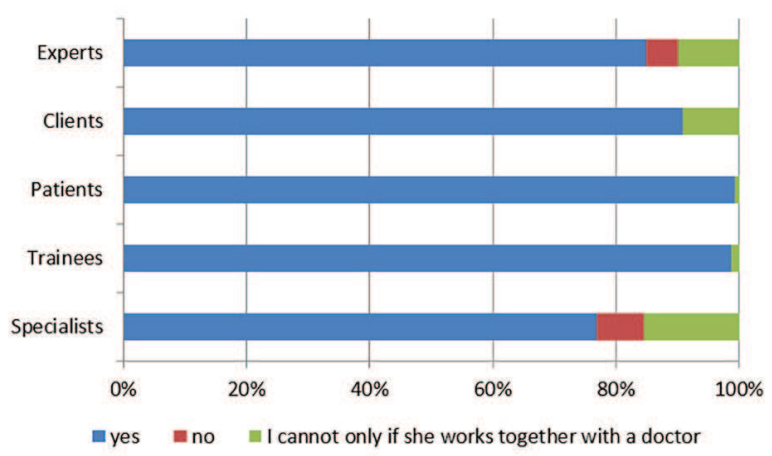

Fig. 2. Opinion of respondents' on their trust in the midwife (comparative data)

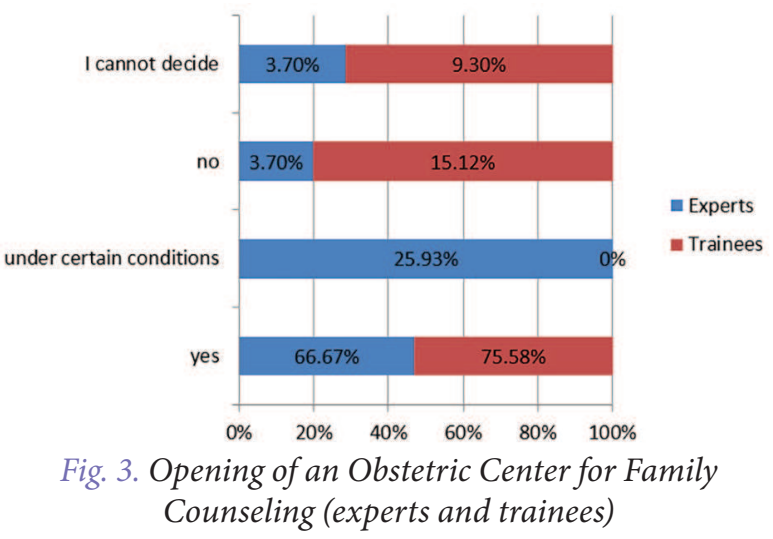

To establish an OCFC, we need to analyze a number of factors and attitudes of the leading municipal bodies, the ways to fund operations, readiness of midwives, etc., related to the process. Based on a series of studies on the discussed problem we can schematically present the possibility of starting a center in the way shown on Figure 4. The readiness of the Municipality is indicated by a yellow light - that is there are still insurmountable obstacles and these are - impossibility of the midwives to sign contracts with NHIF and for this reason they are unable to finance similar activities (marked with red light). Green light is set to the trust of patients to receive service at an OCFC and the readiness of midwives to work in such structure. Unsolved problems, which we have marked with yellow lights, are the legal framework, the lack of regulation for the introduction of obstetric records and the need to adopt the standards of healthcare in line with the good obstetric practice (Fig. 4).

What might be the benefits of establishing an OCFC?

1. Available innovative model for providing autonomous obstetric care through training and advisory activities (OCFC) with potential:

$\diamond$ obstetric family counseling for a large number of women - pregnant women and mothers from marginal groups, which at this stage remain outside the health system;

$\diamond$ increasing the health awareness of marginalized groups for normal pregnancy, parenting and raising children;

$\diamond$ reducing health inequalities among pregnant women and mothers of young children and facilitating their equal access to health services; 

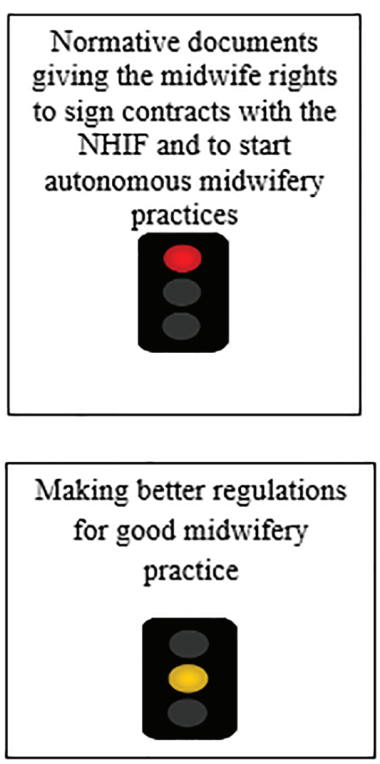
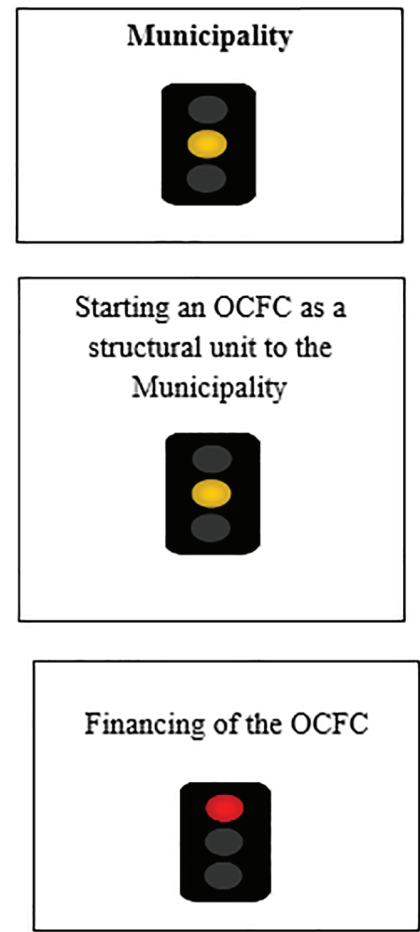

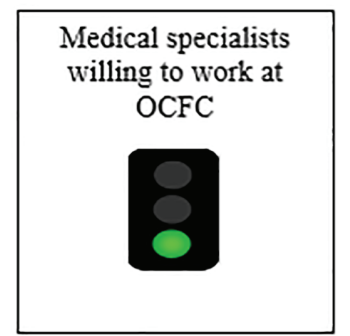

Patients, ready to take advantage of the health care service at the OCFC

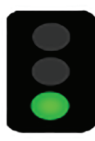

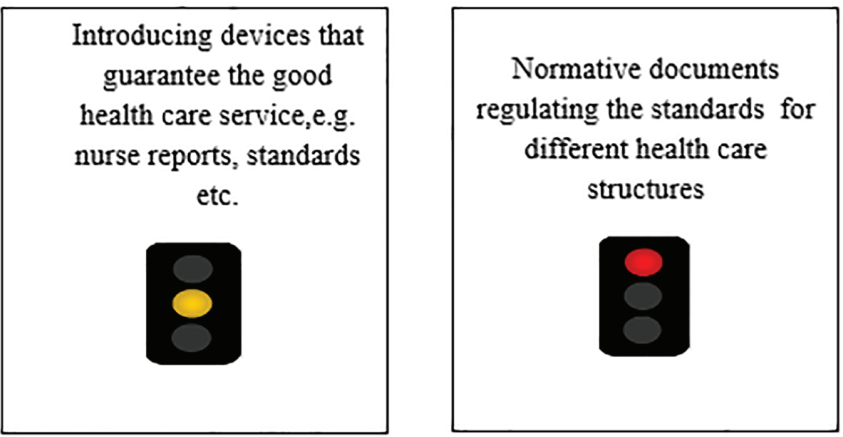

Fig. 4.

$\diamond$ prestige of midwives.

2. The model of an OCFC can have economic efficiency and can guarantee health insurance coverage of pregnant women at a lower cost.

\section{CONCLUSIONS}

1. The establishing of an OCFC structural unit of the Municipality can be a mobilizing factor and challenge for the modern obstetric community in Bulgaria.

2. The absence of a clear legislation giving midwives the right to sign contracts with NHIF limits their ability to open private obstetric practices.
3. The academically prepared midwife gives healthcare system in Bulgaria a significant resource that can be directed to the consultative work with pregnant women and mothers who need support and encouragement.

\section{REFERENCES}

1. Alexandrova M. Models for continuous training of nurses. In: Proceedings of scientific studies and stages of SWU "Neophyte Rilski” - Modern education - mission and vision. Blagoevgrad: Univ. ed. "Neophyte Rilski"; 2010: 459-462.

2. National Programme for improving maternal and child health 2014-2020, adopted by Decision № 510 of the Council of Ministers 17.07.2014. 
3. 3. National Strategy of the Republic of Bulgaria for Roma Integration (2012-2020) Framework Programme for Integration of Roma in Bulgarian Society $(2010-2020)$

4. Tontcheva S, et al. Attitudes and willingness of midwives to perform autonomous operations. Health Care. 2012; 1: 9-16.

5. Tontcheva S, Dimitrova. The role of the midwife in counseling women. Trakia Journal of Sciences. 2008; 6 (4): 44-48.

6. Tontcheva S. Creation of a small obstetric consultation center for a course for normal pregnancy and postpartum period for midwives. 2012, № 6, p. 32-39

7. Council conclusions on an EU Framework for National Roma Integration Strategies up to 2020, Brussels, Council of the European Union, 2011

8. Corrigan E. Nurses as equals in the multidisciplinary team. Hum Fertil

(Camb). 2002, 5 (Suppl 1): 37-40

9. EU Strategic Framework on Health and Safety at Work 2014-2020

10. 1Health 2020: An European policy framework and strategy for the $21^{\text {st }}$ century

11. Health and the Roma community, analysis of the situation in Europe. Madrid, Fundacion Secretariado Gitano, 2009. 